\title{
Estágio supervisionado: compartilhando as experiências e os desafios para o ensino de Química no Amazonas
}

Stage supervised: sharing the experiences and the challenges for the chemistry teaching in Coari-Amazonas

Leiliane de Almeida Freitas ${ }^{1}$

Ercila Pinto Monteiro ${ }^{2}$

\section{Resumo}

Esta pesquisa relata a importância dos estágios e do projeto de intervenção na formação dos professores, e, para tal, compartilha experiências dos Estágios Supervisionados de I ao IV realizados na Escola Estadual Alexandre Montoril/Amazonas. O desafio de se tornar um professor de Ciências na região amazônica requer do licenciando propostas inovadoras que superem ausência de recursos didáticos, normalmente, não disponíveis nas escolas. Assim, considerando as particularidades regionais, foi realizado um projeto de intervenção a partir da vivência dos estágios da licenciatura Biologia/Química que apresenta como recurso didático pigmentos naturais extraídos de frutas típicas da região. $\bigcirc$ trabalho envolveu vinte (20) alunos do $2^{\circ}$ ano do Ensino Médio e se concretizou por meio da relação dos conceitos científicos com o universo amazônico. Das atividades propostas com os pigmentos, estão quatro (4) experimentos, sendo eles: dois (2) de indicador natural, um (1) sopro químico e um (1) de cromatografia. Em geral, os resultados desta pesquisa mostram que os extratos aquosos de pigmentos da Amazônia se apresentam como um recurso didático inovador e estratégico nas aulas de Química, porque os alunos previamente já apresentam conhecimentos culturais referentes às frutas da região. Neste contexto, os experimentos se tornaram "instrumentos facilitadores" para apropriação dos conceitos científicos e fundamentais para o processo de ensino-aprendizagem.

Palavras-chave: ensino de química, recurso didático, aulas experimentais.

\section{Abstract}

This research reports the importance of internships and of the project of intervention in the training of teachers, and to this end, it shares experiences in the supervised internships from I to IV carried out at the Alexandre Montoril/Amazonas State School. The challenge of becoming a science teacher in the Amazon region requires from the licensing innovative proposals that overcome the lack of teaching resources, usually not available in schools. Thus, considering the regional peculiarities, an intervention project was carried out from the experience in the internships at the Biology/Chemistry undergraduate that presents as

\footnotetext{
${ }^{1}$ Secretaria de Estado de Educação do Amazonas | leila_daf@hotmail.com.

${ }^{2}$ Universidade Federal do Amazonas | monteiro@ufam.edu.br.
} 
teaching resource natural pigments extracted from typical fruits of the region. The work involved twenty (20) students of the 2nd year of high school and was materialized through the relationship of scientific concepts with the Amazon universe. Among the activities proposed with pigments are four (4) experiments: two (2) of natural indicators, one (1) of chemical breath and one (1) of chromatography. In general, the results of this research show that the aqueous extracts of pigments from the Amazon present themselves as an innovative and strategic educational resource in chemistry classes, because the students previously present cultural knowledge regarding the fruits of the region. In this context, experiments have become "enabling instruments" for the appropriation of scientific concepts, so fundamental to the teaching-learning process.

Keywords: Chemistry education, teaching strategy, experiments

\section{Introdução}

\section{Compreendendo os estágios supervisionados do curso de Licenciatura em Ciências: Biologia/Química}

As disciplinas de Estágios Supervisionados do curso de licenciatura em Ciências: Biologia e Química da Universidade Federal do Amazonas são oferecidas durante quatro semestres seguidos e estão divididas em Estágio Supervisionado I a IV. Em cada estágio o estudante da licenciatura busca compreender o funcionamento do ambiente escolar por meio da observação e da regência sempre sob a orientação e acompanhamento do professor-supervisor da escola e do professor universitário responsável pela disciplina.

No Estágio Supervisionado I, o licenciando realiza a observação reflexiva sobre o funcionamento da escola, que se apresenta muito diferente daquela mera observação neutra e descritiva. Esse é um momento que o licenciando necessita alcançar uma visão sociológica para ir além da descrição. É comum que os alunos no primeiro estágio se preocupem mais com o "registro quantitativo", ou seja, com o número de salas de aula, de laboratório, de biblioteca, entre outros, do que com as relações sociais, culturais e políticas que perpassam esses ambientes. Dessa forma, a figura do professor universitário se torna central na mediação do diálogo entre a teoria e a prática para que os aprendizes reflitam sobre a realidade escolar.

No Estágio Supervisionado II, o licenciando vivencia mais de perto o processo de ensino-aprendizagem e observa o professor da escola em sala de aula. 0 acompanhamento do estagiário nas aulas do professor da escola exige dele uma reflexão profunda sobre as relações sociais estabelecidas em sala de aula, das quais estão: (1) professor-aluno, (2) aluno-conhecimento, (3) aluno-aluno, (4) aluno-tecnologia, entre outros, e também do modelo de ensino adotado pelo professor, as avaliações, as concepções e crenças sobre ciências.

Os Estágios Supervisionados III e IV se concretizam com a etapa de ação, pois é o momento que o licenciando realizará a regência. Nesta etapa, é importante que os alunos aprendam o sentido do planejamento e a visão do professor sobre o que é planejar, pois é durante a regência que o licenciando perceberá os enormes desafios enfrentados pelos professores das escolas, principalmente, quanto às estratégias didáticas que o educador deve recorrer, devido, principalmente, à heterogeneidade das turmas. 
Compreende-se que a experiência adquirida durante a regência produz maturação necessária para o licenciando construir um projeto de intervenção na escola, que aponte solução para um problema observado por ele. Considera-se, portanto, neste artigo, o compartilhamento da experiência vivenciada durante o estágio e mais os resultados de um projeto de intervenção.

\section{Reflexões sobre o Estágio Supervisionado}

O Estágio Supervisionado do curso de licenciatura consiste em uma etapa fundamental de formação, porque coloca a reflexão como instrumento de cientificidade para uma análise teórica do saber-fazer em sala de aula, que ultrapassa as meras reproduções do conhecimento. Manifesta-se como a dialética teórico-prática que conduz o estudante à prática da razão inventiva, revelando o construto teórico da ciência e se tornando indispensável para a formação do pensamento crítico (BARBOSA e BULCÃO, 2004). É nessa etapa que o licenciando inicia o "primeiro contato" com o seu campo de atuação profissional e se vê, portanto, no confronto com a realidade escolar. É quando as problemáticas da educação parecem ser mais evidentes, exigindo a reflexão do licenciado sobre a escola que se apresenta a ele e aquela que ele deseja construir, possibilitando, assim, o seu crescimento intelectual (PIMENTA, 1997).

Como coloca Soares et al (2007),
É durante o estágio que os futuros professores irão confrontar suas crenças educacionais, desenvolvidas ao longo de sua formação, com a realidade da sala de aula, podendo desenvolver conflitos ou preocupações educacionais, especialmente em contextos que afrontem essas crenças.

Cada etapa do estágio requer uma atenção especial, começando pelo diagnóstico da escola no primeiro estágio supervisionado, que não se configura em uma mera coleta de dados, mas uma pesquisa da dinâmica, das relações, da estrutura física, dentre outras características, que revelam como o ensino se configura na instituição. Estes são fatores que estão proporcionalmente ligados à qualidade de educação oferecida pela escola. A observação se configura como uma etapa esclarecedora para o licenciando à medida que ele compreende o funcionamento do ambiente escolar. Esse é o momento de conhecer a turma, a faixa etária dos alunos, o número de alunos em classe, as dificuldades e as possibilidades do ensino de conteúdos. Depois dessa primeira etapa diagnóstica, a outra se configura por meio da regência que exige do aluno a sua ação no saber-fazer da sala de aula, que, em conjunto com o professor colaborador, busca-se a compreensão prática da função do plano de ensino e da relação binominal: professor-aluno, teoria-prática, ensinoaprendizagem, não para reprodução de modelos prontos, mas pela renovação com a inserção de novas práticas (PIMENTA e LIMA, 2004).

O desafio para o licenciando na regência (ministração de aula) é ainda maior, pois as dificuldades parecem ser mais evidentes. Dada à importância dos recursos didáticos, do laboratório de ciências e de outras estratégias importantes, o licenciando começa a perceber os enormes desafios pela frente, em vista de uma profissão que é desvalorizada. São vários os questionamentos que são colocados pelos estudantes na universidade, dentre os mais frequentes são: como ensinar ciências sem laboratório? Como enfrentar as 
dificuldades conceituais dos alunos? Como propor novas estratégias de ensino? As perguntas parecem não acabar.

No caso particular do Amazonas, onde geograficamente o acesso aos recursos da capital é inviabilizado pela impossibilidade de transporte rodoviário, torna-se ainda mais difícil pensar em laboratório de ciências. É o caso do município de Coari/AM, que estando aproximadamente a $345 \mathrm{~km}$ de distância da capital Manaus sofre com a falta de recursos didáticos e de acesso a laboratórios de ciências nas escolas.

A vivência em sala de aula aos poucos vai revelando o significado da teoria aprendida durante a graduação e se de fato a escolha do curso feita pelo graduando é algo que ele se identifica. Talvez para alguns seja um momento de crise e impacto de uma realidade dura e difícil, onde os desafios parecem ser incontáveis (MILANESI, 2012). Outros aspectos vão se somando à realidade, como desvalorização salarial, precarização escolar e o desestímulo dos próprios professores da escola em revelar aos licenciandos a profunda "desilusão" de ser professor, a ponto de perguntarem aos estagiários: "O que você faz aqui? Procure outro curso, ser professor não é futuro para ninguém" (esse é o relato de alguns licenciandos).

É por meio desse ambiente de desestímulo da profissão que os alunos de estágio encontram os professores da escola. Mesmo com as dificuldades existem professores de escolas públicas que buscam relacionar a teoria e a prática levando para a sala de aula experimentos, promovendo aulas demonstrativas, investigativas ou verificativas, tentando desenvolver estratégias didáticas para o ensino de Ciências (OLIVEIRA, 2010; TAHA et al 2016). Outras dificuldades também surgem no acesso aos materiais, que, às vezes, mesmo sendo de baixo custo ainda é restrito em alguns lugares. Em Coari, por exemplo, é difícil encontrar o repolho roxo muito usado como material alternativo em substituição aos indicadores sintéticos para a identificação de substâncias ácido-básicas em experimentos de química, pois nas feiras dos municípios do interior esse produto é praticamente inexistente.

Nesse caso, os saberes locais muitas das vezes revelam singularidades que são desconsideradas na construção do currículo, principalmente, quando se trata de uma região com "particularidades" como é o caso do Amazonas. No Brasil, ainda se busca modelos curriculares estrangeiros baseados em parâmetros muito distantes de nossa realidade, para se conceituar e oferecer uma "educação de qualidade" (LIMA e TEXEIRA, 2017). A falta de autonomia dos professores na construção de um currículo próprio para a escola, em vista de determinações externas (como as Diretrizes Curriculares que ficam responsáveis em determinar boa parte), inviabiliza a apresentação de um currículo "mais aberto" para a complexidade Amazônica, tornando o currículo atual ineficiente e descontextualizado. Por isso Gadotti (2000) afirma:

As mudanças que vêm de dentro das escolas são mais duradouras. Da sua capacidade de inovar, registrar, sistematizar a sua prática/experiência, dependerá o seu futuro. Nesse contexto, o educadoré um mediador do conhecimento, diante do aluno que é o sujeito da sua própria formação. Ele precisa construir conhecimento a partir do que faz e, para isso, também precisa ser curioso, buscar sentido para o que faz e apontar novos sentidos para o que fazer dos seus alunos.

Essa dificuldade torna-se mais evidente para os licenciandos durante os estágios supervisionados, porque é o momento em que eles se aproximam da escola e vivenciam os momentos de dificuldades presentes nas atividades do professor. De acordo com Johwan, Basso e Oliveira (2005): 
A vivência escolar é um momento privilegiado na construção da cidadania. O conhecimento oferecido pela escola deve ser o da realidade, por isso ela precisa capacitar o aluno para que saiba, diante da complexidade do mundo real, posicionar-se, orientar suas ações e fazer opções conscientes no seu dia a dia.

O aluno de estágio precisa perceber as singularidades da escola, buscando teorizar a sua realidade (MILANESI, 2012). Para tal, é necessário recorrer a uma reflexão sobre a história da educação escolar, de modo a compreender o quanto ela foi e ainda é marcada pelas relações de poder, tornando o conhecimento uma categoria política. A escola não é neutra, ela se torna um veículo de difusão ideológica do conhecimento, que é determinado por certos grupos da sociedade, conforme os seus interesses (BOURDIEU, 2013). Uma das reflexões feitas por Bourdieu é de que precisamos pensar se a culpa é do destino ou do sistema capitalista que impõe as suas regras.

São nos momentos de reflexões que essas questões se tornam manifestas e evidentes. Alguns pesquisadores acreditam que a reflexão é o procedimento necessário para a construção do conhecimento (STENHOUSE, 1984; BOURDIEU, 2012; LUGLE e MAGALHÃES, 2013). Por isso que as pesquisas apontam a necessidade dos cursos de licenciatura oferecerem para o licenciando uma formação que desenvolva as características de um professor reflexivo, para que ele aprenda a analisar as ações e as relações escolares e busque compreendê-las (CONTRERAS, 2002; CARVALHO e DARSIE, 1996). Outro aspecto em que se pode evidenciar o ato reflexivo é o planejamento. De acordo com Padilha (2001),

o ato de planejar é sempre processo de reflexão, de tomada de decisão sobre a ação; processo de previsão de necessidades, visando à concretização de objetivos, em prazos determinados e etapas definidas, a partir dos resultados das avaliações.

No ato da reflexão como instrumento de cientificidade é que se acredita despertar nos estudantes de licenciatura, a busca por construção de projetos de intervenção associados à realidade escolar, pois a experiência dos estágios supervisionados deve encaminhar os estudantes de licenciatura a um repensar das ações e práticas escolares. Seria o mover dos saberes adquiridos durante os períodos de aprendizagem social, cultural, escolar e profissional que estão dinamicamente entrelaçados. Neste contexto, as dificuldades observadas não podem se impor como barreiras, mas como algo a ser superado, onde o repensar sobre os momentos pedagógicos, as práticas e didáticas oferecidas, as relações sociais estabelecidas em classe, entre outras, devem ser estimuladas no estudante. Foi assim que os estudantes do curso de Ciências em Coari-AM conduziram os seus estágios, na busca de compreender a escola e de construir projetos alternativos de intervenção capazes de se adaptar à realidade vivida.

\section{Ensino de Química e Interdisciplinaridade}

A química é uma área do ensino que possibilita o aluno obter uma visão de mundo sobre a composição e as transformações da matéria, a partir dos modelos teóricos construídos pelo homem divulgados através da ciência. A ciência possui um "corpus" de conhecimentos que possibilita o homem compreender parte do sentido do mundo e da vida, e a manipular a matéria para o desenvolvimento da agricultura, da alimentação, das 
doenças, das composições, entre outros (AIKENHEAD, 1997). Portanto, é muito importante que o ensino de ciência esteja fazendo parte das discussões em sala de aula.

Os aspectos didáticos em sala de aula para o entendimento dessa disciplina devem considerar o abandono das aulas memorísticas, conteudistas e a descontextualização dos conceitos, potencializando a compreensão do mundo de forma mais instigante e interessante. Cabe assinalar que sendo a química uma construção humana, as razões e os objetivos que justificam e motivam o ensino desta disciplina também devem considerar as falhas e os erros apresentados durante a construção de suas teorias, acompanhados de suas respectivas retificações (BACHELARD, 1978; FOUREZ, 1995).

Essa é a grande dificuldade dos professores de Química na atualidade, tendo em vista uma formação passiva, cartesiana e fragmentada, apesar de atuais pesquisas em "educação em ciências" apontarem novos caminhos didáticos. Pode-se dizer que a educação em química é considerada uma área nova, que já mostra a sua força pela construção de uma sólida comunidade de pesquisadores da área, como afirmam BEJARANO e CARVALHO (2000):
Outra forma de ver o ensino de Química é observá-la através das pesquisas e publicações realizadas pela comunidade de educadores químicos [...]. As dificuldades que emergem da opção metodológica de se falar do ensino de Química, através das pesquisas nessa área, estão ligadas, como poderemos observar, à própria juventude da pesquisa em Educação Química em nosso país. Juventude entendida não como tempo decorrido dos primeiros trabalhos acadêmicos da área, que se iniciaram no início da década de 1970, mas como um tempo necessário para que se firme como uma sólida comunidade de pesquisadores do ensino de Química.

A falta de professores é uma realidade presente em todo o Brasil e se torna mais grave em regiões onde o acesso aos recursos é ainda menor, como é o caso do Estado do Amazonas. Apesar de a situação ser grave, o quadro precisa ser revertido, podendo acontecer através de investimento na formação de professores, principalmente, nessa região (EVANGELISTA e CHAVES, 2010). Em muitas zonas rurais de municípios do Amazonas, o problema da falta de professores tem sido resolvido com o ensino de mediação tecnológica (TEIXEIRA e MONTEIRO, 2009), onde o ensino é oferecido por meio do auxílio virtual. Aqueles professores que trabalham nessa região, com muito esforço, buscam muitas vezes transformar sua aula em ambientes interativos para melhor compreensão dos conceitos de química. Como é o caso dos projetos citados a seguir: Costa e Mesquita (2010) sobre a "Química na praça"; de Soares e Costa (2010) sobre ludicidade; oficinas de química de Oliveira et al. (2010); experimentos com pigmentos naturais de Couto, Ramos e Carvalho (1998) e também de Monteiro, Silvia e Nascimento (2014).

Outro desafio no Amazonas é considerar o seu grande território que abarca inúmeras diversidades, não apenas biológicas, mas também culturais, onde a população apresenta as suas peculiaridades. Assim, cabe também aos profissionais da química desenvolver atividades na região Norte, considerando sua parcela de responsabilidade para com as características regionais, para, então, produzir novos conhecimentos e tecnologias adaptados ao dia a dia amazônico (Arruda, 1997). Neste contexto, torna-se evidente que a interdisciplinaridade e a contextualização são itens indispensáveis para o ensino da região 
Norte, pois contribui para o processo de ensino-aprendizagem e para a aproximação com a realidade.

As publicações na literatura mostram quanto o termo interdisciplinaridade gera discussões em relação a sua definição. Por um lado, existem autores que defendem a interdisciplinaridade pelo "nível de interação real entre as disciplinas", como afirmam Hernandéz e Ventura (1998), Japiassú (1976) e Zabala (2002), que defendem a tentativa de integração entre as diferentes disciplinas. A interdisciplinaridade se dá, portanto, em função da prática e do agir, apresentando-se como um processo integrador e articulador, cuja pretensão das diferentes atividades desenvolvidas é ser conduzida para a discussão de um mesmo tema.

Para outros autores, a interdisciplinaridade se apresenta como a articulação de saberes e não apenas nos limites disciplinares. Isso amplia suas pretensões, visto que a ação pedagógica aponta para a construção e a interação dos diversos conhecimentos em busca de uma escola participativa e na formação do sujeito social. Assim como afirma Gadotti (1999):
O seu objetivo tornou-se a experimentação da vivência de uma realidade global, que se insere nas experiências cotidianas do aluno, do professor e do povo e que, na teoria positivista, era compartimentizada e fragmentada. Articular saber, conhecimento, vivência, escola, comunidade, meio ambiente e etc. tornou-se, nos últimos anos, o objetivo da interdisciplinaridade que se traduz, na prática, por um trabalho coletivo e solidário na organização da escola.

No que tange à legislação brasileira, os Parâmetros Curriculares Nacionais (PCN) se manifestam em compreender a interdisciplinaridade da seguinte maneira:
A interdisciplinaridade supõe um eixo integrador, que pode ser o objeto de conhecimento, um projeto de investigação, um plano de intervenção. Nesse sentido, ela deve partir da necessidade sentida pelas escolas, professores e alunos de explicar, compreender, intervir, mudar, prever, algo que desafia uma disciplina isolada e atrai a atenção de mais de um olhar, talvez vários (BRASIL, 2002, p. 88-89).

Entende-se, portanto, que compreender a "integração" como eixo da interdisciplinaridade dentro da realidade plural Amazônica é valorizar a sua complexidade. Dentro de um espaço de diversidade cultural, é possível encontrar diferentes saberes. Esses saberes são de pertencimento, que identifica o homem amazônico em sua totalidade. Os saberes dos indígenas, dos ribeirinhos, dos pescadores, dos quebradores de castanha, dentre outros são os que mantêm seus valores e costumes, além de resolver problemas do dia a dia. É neste cenário de pluralidade que o aluno da Amazônia se integra à escola. 0 estudante da Amazônia, principalmente, de zona rural chega à escola com uma subjetividade formada pela cultura local, carregada de simbolismo e de representações. Esses conhecimentos não podem ser estigmatizados, pois pertencem a sua cultura e a sua visão de mundo. O papel da escola, portanto, seria de ampliar a sua visão, apresentando a visão científica como uma das maneiras criadas pelo homem para explicar o mundo e que, sendo uma aproximação, deve dialogar com a visão de mundo do aluno (COBERN e AIKENHEAD, 1997). 
A proposta de um pensamento complexo nos ajuda a refletir sobre a integração do conhecimento químico com outros saberes. É contestável que, estando na Amazônia, o licenciado em química não conheça os aspectos sociológicos e históricos da Amazônia para fazer relação dos conceitos químicos com os saberes populares, indígenas, ribeirinhos etc. É preciso que ele conheça a sua região e suas peculiaridades, ou seja, que desenvolva um pensamento complexo, ultrapassando os limites do saber escolar e estabelecendo o diálogo com as diversas dimensões do conhecimento. Esse diálogo possibilita uma formação articulada com outros saberes, não se restringindo à unidade científica. Portanto, os conhecimentos não devem ser transmitidos, mas articulados, construídos, discutidos, reformulados, repensados, passando pela análise crítica e reflexiva.

Considerando que o pensamento complexo é um modo de incluir as peculiaridades da região amazônica e apresentar novas possibilidades para o ensino de ciências local, foi que surgiu o projeto de intervenção para o estágio supervisionado. Sendo a região amazônica rica em biodiversidade conhecida pelos moradores locais, construiu-se um projeto que vinculasse os conhecimentos locais provenientes dessa biodiversidade com a química. Dessa forma, buscou-se, através dos pigmentos naturais presentes em frutas regionais, a extração de indicadores ácido-base que tivesse potencial em identificar substâncias ácidas e básicas, além de realizar outros experimentos. $O$ uso desses pigmentos em atividades didáticopedagógicas de química se mostraria como uma alternativa didática interessante para integração dos alunos e a aprendizagem de conceitos da química.

Portanto, a pretensão deste trabalho é compartilhar as experiências e os resultados das atividades realizadas durante o projeto de intervenção do Estágio Supervisionado IV na Escola Estadual Prefeito Alexandre Montoril, Coari/AM. Esse projeto foi uma experiência integradora e desafiante para quem tem pretensão de ensinar química no Estado do Amazonas e que contribuiu grandemente para a minha formação, enquanto estudante de licenciatura.

\section{Metodologia da pesquisa}

\section{Local da Pesquisa}

A pesquisa foi realizada na Escola Estadual Alexandre Montoril, localizada no município de Coari/AM na microrregião do Médio Solimões. Com uma distância de 362,84 km em linha reta da capital Manaus, Coari possui 75.963 mil habitantes (IBGE, 2010) e é considerada a segunda cidade mais rica do Estado por possuir uma base de exploração de petróleo da Petrobras em Urucu. No entanto, nos últimos anos, a cidade passa por instabilidade política e econômica e recebeu, no ano de 2006, um dos polos permanentes da Universidade Federal do Amazonas que oferece vários cursos de graduação e entre eles o de licenciatura em Ciências: Biologia e Química. 


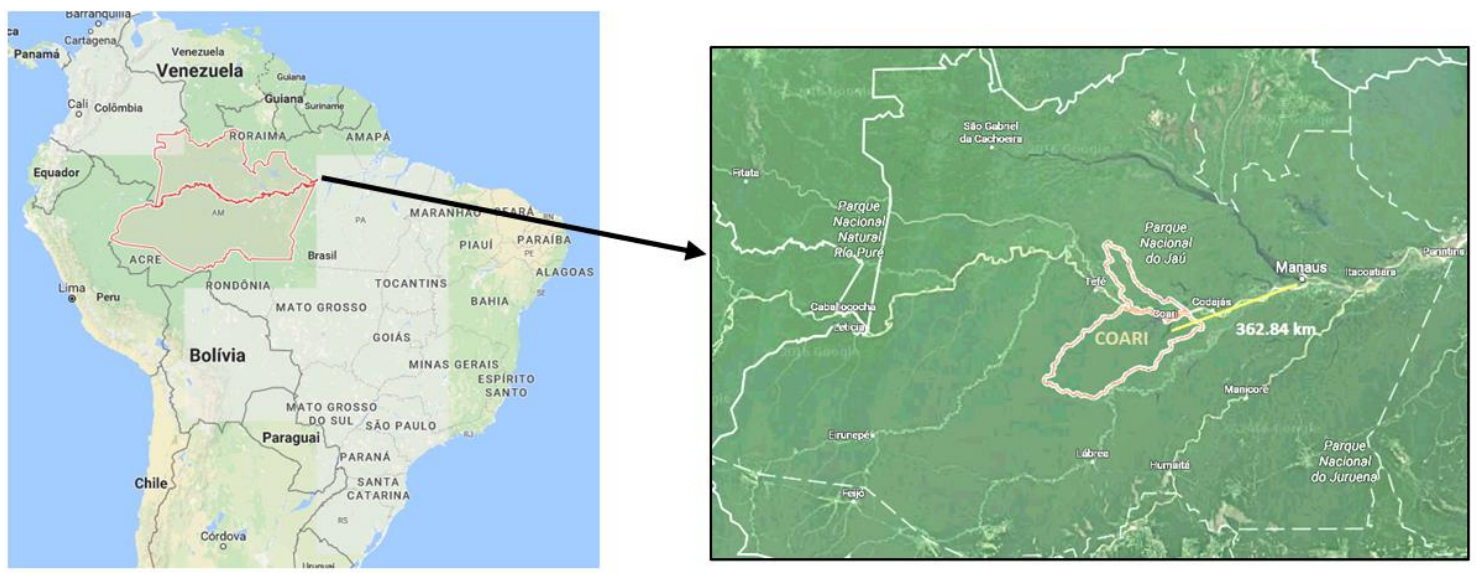

Figura 1 - Mapa de Coari, Amazonas. Fonte: Google Maps. Fonte: Google. 


\section{Procedimento Metodológico}

Esta pesquisa segue o viés qualitativo por considerar as subjetividades dos estudantes e do professor em relação ao processo de ensino-aprendizagem de química, fazendo uma análise exploratória a respeito da abordagem do professor, do interesse pela disciplina de Química, do conhecimento sobre pigmentos, entre outras. Para tal análise, participaram da pesquisa vinte (20) alunos e uma (1) professora de Ciências da turma do $2^{\circ}$ ano do Ensino Médio noturno, por um período de 15 dias, em novembro de 2010, sendo eles da faixa etária de 16 a 49 anos. Os dados da pesquisa foram registrados fazendo uso da observação participante e do questionário (CRESWELL, 2007) como instrumentos analíticos, que ocorrem durante a ação do projeto de intervenção. O projeto foi construído a partir da problemática da falta de recursos didáticos em aulas de Química, observada durante os estágios. Assim, buscou-se desenvolver experimentos simples com pigmentos naturais extraídos de frutas amazônicas para o ensino de Química. Para tal, foi necessário planejar a construção e a elaboração da proposta em duas etapas: (1) no laboratório da Universidade e (2) na Escola. No laboratório da Universidade, durante o período de seis (6) meses, a pesquisadora extraiu e fez testes com os pigmentos naturais de três frutas regionais (Tabela 1), conseguindo construir os roteiros de quatro (4) experimentos, cujo objetivo era relacionar os conceitos culturais com os conceitos científicos (Tabela 2). Em seguida, partiuse para a atividade na escola, a qual é descrita a seguir.

\section{Atividades nas aulas de Química}

Tabela 1 - Frutas Amazônicas usadas na pesquisa.

\begin{tabular}{c|c|c|c}
\hline \multirow{2}{*}{ Nome popular } & $\begin{array}{c}\text { Nome } \\
\text { Científico }\end{array}$ & Características \\
\hline Mapati & $\begin{array}{c}\text { Pourouma da Amazônia } \\
\text { Cecropiifolia }\end{array}$ & $\begin{array}{c}\text { Uva da Amazônia, fruta doce, } \\
\text { cor de vinho, casca grossa e de } \\
\text { sementes. }\end{array}$ \\
\hline Bacaba ou & $\begin{array}{c}\text { Oenocarpus } \\
\text { bacaba }\end{array}$ & $\begin{array}{c}\text { Proveniente de palmeira, fruta } \\
\text { de semente, semelhante ao açaí, } \\
\text { cor de vinho, apresenta cachos }\end{array}$ \\
\hline Mari-mari ou & $\begin{array}{c}\text { Poraqueiba } \\
\text { sericeia Tul }\end{array}$ & $\begin{array}{c}\text { Predominante no Alto Rio } \\
\text { Negro, Solimões e na região do } \\
\text { Madeira, fruteira de porte } \\
\text { médio, que pode alcançar até 15 } \\
\text { metros de altura, folhagem } \\
\text { ramificada, flores amarelo-clara. }\end{array}$ \\
\hline
\end{tabular}

Considerando as contribuições de Morin (2011) de que a ciência não é uma unidade fechada, mas está aberta para se relacionar com outros saberes, buscou-se um diálogo com os alunos de modo a discutir os saberes locais sobre as frutas amazônicas e os conhecimentos científicos. Para tal, foi entregue um questionário aos alunos com perguntas 
sobre pigmentos e, posteriormente, foi feita uma discussão. É importante considerar que os conceitos teóricos já haviam sido trabalhados pela professora em sala, de modo totalmente teórico. Buscou-se, durante as atividades, questionar os alunos a respeito dos pigmentos naturais, tendo o cuidado de não transmitir diretamente os conceitos, mas articulá-los, discuti-los, repensá-los, construí-los, passando pela análise crítica e reflexiva. O objetivo foi ampliar o conhecimento deles, fazendo as discussões a partir de experimentações com frutas regionais. As frutas amazônicas utilizadas no experimento para a construção de conceitos da química são bem conhecidas pelos alunos através de seus nomes populares (Tabela 1).

Após a discussão sobre "pigmentos", os alunos fizeram uma oficina em sala com a realização de três experimentos (Tabela 2). Os trabalhos foram realizados em grupos de quatro, tendo em média de 4-5 alunos, os quais tiveram uma semana para prepará-los e rever os conceitos para apresentá-los em classe. Para isso, cada grupo recebeu um roteiro com as orientações sobre o experimento vinculado ao conceito teórico que seria estudado. Foi solicitado que cada grupo apresentasse o experimento explicando o fenômeno teoricamente. O objetivo da pesquisadora foi avaliar por meio da observação-participante a relação teoria-prática, interação professor-aluno e aprendizagem dos conceitos que eles tinham por meio da indagação.

Tabela 2 - Conceitos de química construídos em classe a partir de experimentos com pigmentos naturais.

\begin{tabular}{c|c|c}
\hline Frutas & Experimentos & Conceitos \\
\hline Oenocarpus bacaba & Indicador natural & Ácido-base \\
\hline Pourouma Cecropiifolia & Indicador natural & Ácido-base \\
\hline \multirow{2}{*}{ Poraqueiba sericeia Tul } & Sopro Químico (casca) & Equilíbrio Químico \\
\cline { 2 - 3 } & Cromatografia (Folha da planta) & Afinidade molecular \\
\hline
\end{tabular}

Os pigmentos naturais extraídos dos frutos regionais foram preparados pelos alunos sob orientação da professora e da pesquisadora, sendo utilizados, posteriormente, em três atividades.

\section{Resultados e Discussões}

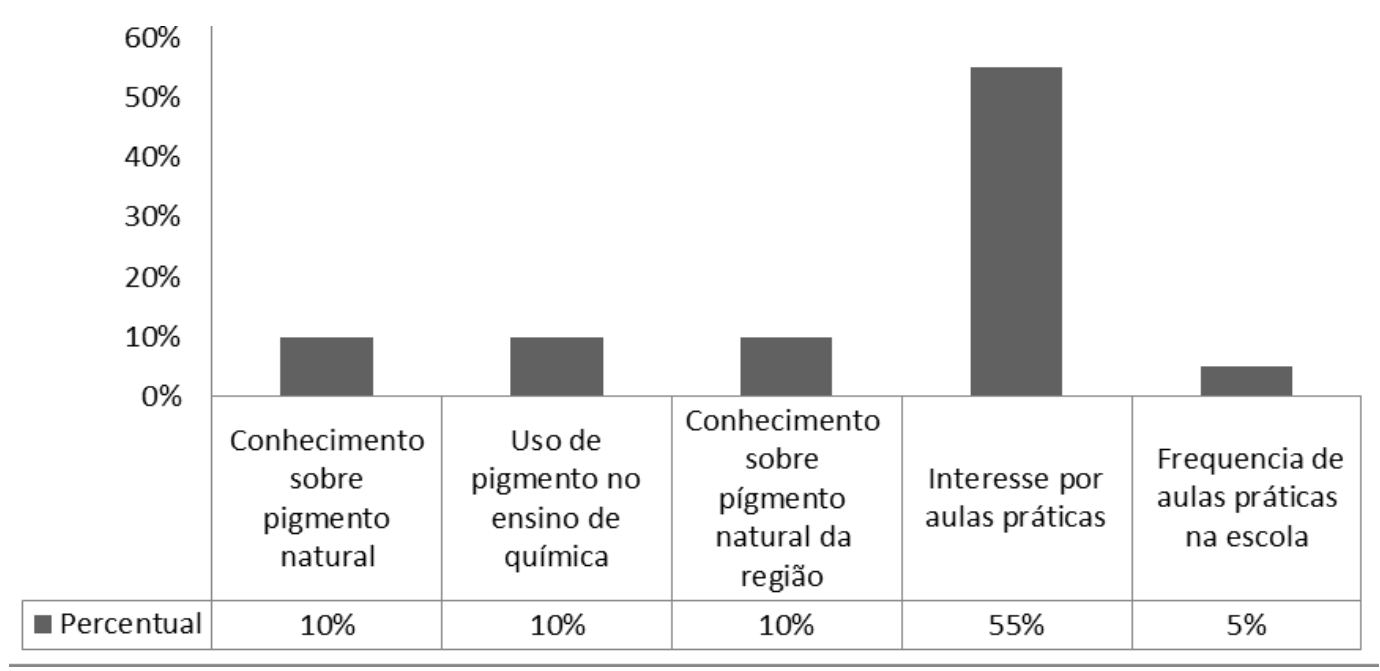


Figura 2- Percentual representativo das respostas dos alunos participantes da pesquisa quanto aos pigmentos naturais e às aulas práticas. Fonte: Pesquisadora

Quando os alunos foram questionados sobre os pigmentos, os resultados mostraram que eles tiveram dificuldade em fazer a relação da "cor das frutas" com a "presença de pigmentos". A maioria demonstra desconhecer a existência de pigmento, apesar de conhecer as frutas. Um representativo de 10\% dos estudantes afirma conhecer a existência de pigmentos naturais, porque já ouviu o termo nas mídias e ou mesmo em casa, mas não souberam definir (Figura 2). Eles ficaram surpresos em conseguirem extrair o pigmento das frutas regionais na preparação do extrato.

Os estudantes também discutiram sobre as aulas de química na escola e manifestaram profundo interesse por aulas práticas, visto que a maioria sente enorme dificuldade em aprender os conceitos científicos por achar muito abstratos, desinteressantes e descontextualizados, apesar de gostar da aula teórica da professora. Eles afirmam que a frequência de aulas práticas na escola é reduzida (representatividade de 5\%) por não existir laboratório de ciências. Durante as oficinas, os alunos apresentaram os experimentos tentando explicar a ocorrência do fenômeno, havendo diversos questionamentos por parte dos colegas e da pesquisadora (Quadro 1). A pesquisadora conduziu os questionamentos em sala de aula para a problematização dos conceitos. Dessa maneira, ela conseguiu abordá-los de modo que os alunos compreendessem a visão científica.

\begin{tabular}{|c|c|c|c|}
\hline \multirow[b]{2}{*}{ Experimentos } & \multirow[b]{2}{*}{ Frutas } & \multicolumn{2}{|c|}{ Observação-participante } \\
\hline & & Relação teoria-prática & $\begin{array}{c}\text { Interação em classe e } \\
\text { problematização dos conceitos }\end{array}$ \\
\hline Indicador natural & $\begin{array}{l}\text { Oenocarpus } \\
\text { bacaba }\end{array}$ & $\begin{array}{l}\text { Compreensão do } \\
\text { conceito de ácido-base } \\
\text { pela mudança de cor }\end{array}$ & $900 \theta$ \\
\hline Indicador natural & $\begin{array}{l}\text { Pourouma } \\
\text { Cecropiifolia }\end{array}$ & $\begin{array}{l}\text { Compreensão do } \\
\text { conceito de acidez e } \\
\text { basicidade, com o } \\
\text { desaparecimento da cor. }\end{array}$ & \\
\hline Sopro Químico & $\begin{array}{l}\text { Poraqueiba } \\
\text { sericeia Tul } \\
\text { (casca da fruta) }\end{array}$ & $\begin{array}{l}\text { Compreensão do } \\
\text { conceito de equilíbrio } \\
\text { químico pela mudança } \\
\text { de cor e retorno à cor } \\
\text { original. }\end{array}$ & \\
\hline Cromatografia & $\begin{array}{l}\text { Poraqueiba } \\
\text { sericeia Tul } \\
\text { (folha) }\end{array}$ & $\begin{array}{l}\text { Compreensão da } \\
\text { separação de mistura } \\
\text { pelo registro de cores no } \\
\text { papel. }\end{array}$ & \\
\hline
\end{tabular}

Quadro 1 - Atividades realizadas em sala de aula pelos alunos.

Esse momento foi importante, porque os questionamentos buscavam trazer nas "falas dos alunos" a sua visão de mundo sobre o fenômeno abordado. Essa visão partia de sua 
vida cotidiana e do conhecimento adquirido na escola em séries anteriores. Como afirma Morin (2011):
Tudo isso incita a uma epistemologia aberta [...] não é um ponto estratégico a ocupar para controlar soberanamente qualquer conhecimento, rejeitar qualquer teoria adversa, e dá-se o monopólio da verificação, portanto, da verdade. A epistemologia não é pontificial, nem judiciária: ela é o lugar ao mesmo tempo da incerteza e da dialógica.

O autor nos convida a refletir sobre a importância do conhecimento científico não ser fechado, mas dialógico, considerando outros conhecimentos, uma vez que a ciência tem a sua importância, mas não é detentora da verdade. Ela se constitui como uma construção histórica e social em permanente transformação e, que, portanto, não tem o poder de subjugar os outros conhecimentos. Trazendo para sala de aula, a apropriação do conhecimento científico se torna importante, à medida que os alunos compreendem que a ciência é uma das maneiras de ver o mundo e tem a sua própria construção. Dessa forma, o conhecimento cultural que o aluno traz para as aulas de ciências não é desconsiderado.

Em relação ao primeiro experimento que envolveu a identificação de substancias ácida e base, eles afirmaram conhecer o termo ácido e base. Alguns relacionaram ácido como uma substância que "queima" em referência ao seu poder corrosivo. Enquanto que em relação à base, poucos souberam explicar. No decorrer do ano a professora já havia ministrado os conceitos em sala de aula, mas mesmo nessa condição os alunos tiveram dificuldades em fazer a relação teoria e prática. Observou-se, portanto, que não houve construção do conhecimento científico, visto que os alunos não sabiam explicar o fenômeno.

Então, partiu-se para um segundo momento, onde a pesquisadora começou a questioná-los sobre o que eles acreditavam ter ocorrido. A problematização ocorreu até os conceitos científicos serem construídos com a mediação da pesquisadora. Considera-se, portanto, relevante o que afirma Pozo e Crespo (2009):

De fato, reduzir a "atitude científica" à aplicação cega de alguns procedimentos preestabelecidos é o oposto do espírito de curiosidade, indagação e autonomia que deve caracterizar a prática científica.

Buscou-se com a indagação dar sentido às práticas, recorrendo-se aos conceitos. Esse foi o momento de reflexão, pois permitiu aos alunos a construção do conhecimento com o desenvolvimento da crítica. A problematização possibilita o aluno compreender o sentido do que se estuda, dando-Ihe significado. É esse ensino instigante que mobiliza o aluno à aprendizagem do aprender a aprender, que deve ser promovido em sala de aula, de modo a romper com o aprender a reproduzir. Concordando, novamente, com Pozo e Crespo (2009), buscou-se considerar que:

A verdadeira motivação pela ciência é descobrir o interesse, o valor de aproximar-se do mundo, indagando sobre sua estrutura e natureza, descobrir o interesse de fazer-se perguntas e procurar as próprias respostas. Neste caso, o valor de aprender é intrínseco àquilo que se aprende, e não alheio a isso.

A apropriação do conhecimento não deve se estabelecer pela imposição, mas pelo diálogo. Assim, por meio da negociação dos significados científicos os alunos manifestaram 
a compreensão do conhecimento, observada por meio das relações que faziam das cores com as propriedades das substâncias e o conceito. Por exemplo, o vinagre de característica ácida apresentava cor vermelha na presença do pigmento natural e isso indicava a produção de íons hidrônios. Outras relações que eles faziam partiram de experiências práticas do dia a dia. Um deles afirmou compreender o porquê do açaí ficar verde, quando se mistura com o sabão. É comum lavar o copo sujo de açaí com sabão e observar a cor mudar para o verde. Eles relataram que a cor verde se mostra como um indicador da base. A literatura mostra que o açaí apresenta pigmento natural com característica ácido-base (BRITO et al, 2011) e que a bacaba, sendo da mesma família botânica, também possui as mesmas propriedades (MONTEIRO, SILVIA e NASCIMENTO, 2014).

A apropriação da linguagem científica é outra evidência que se destaca nesta pesquisa, visto que os alunos passaram a utilizar os termos científicos para descrever os fenômenos. Morin e Prigogine (1996) destacam a importância da linguagem como uma emergência cultural que intermedia a aquisição do conhecimento, contribuindo para o homem se tornar um ser social. A linguagem, portanto, torna-se fundamental no processo de aquisição do conhecimento. Mas é importante destacar a preocupação de que a linguagem da cultura não foi rejeitada, pois se tornou facilitadora para a aquisição de uma nova linguagem, que é a científica. Os alunos passaram a compreender a fala da pesquisadora, partindo de suas próprias falas e por meio da problematização.

Durante a observação-participante foi observado o quanto os alunos se envolveram com as atividades e interagiram com os colegas. A surpresa, a atenção, a argumentação e a participação foram elementos essenciais para a ambientalização da aprendizagem em classe.

A pesquisadora, recebendo uma formação em licenciatura dupla, em Biologia e Química, procurou dialogar a temática "pigmentos naturais" com a biologia também, destacando a importância dos insetos no processo de polinização para a produção de flores e de frutos. O experimento de cromatografia, com uso de folhas de plantas verdes para identificação dos pigmentos: clorofila a, clorofila b, carotenos e xantofilas foi também um exemplo para o ensino das diferentes polaridades que as substâncias possuem.

Os resultados da pesquisa trazem evidências de que é necessário um "ambiente didático" que promova a aprendizagem para que haja apropriação do conhecimento científico. Esse ambiente foi construído coletivamente, partindo, principalmente, da interação e da problematização dos conceitos. Segundo Zuanon (2000), a educação é considerada fonte de desenvolvimento cognitivo, onde se estreitam as relações entre linguagem e aprendizagem, capacitando o indivíduo para interiorizar os códigos e signos culturais para o seu desenvolvimento, isto é, conduzi-lo de um plano interpessoal a um plano intrapessoal. Neste contexto, os sujeitos envolvidos, no caso o aluno e seu mediador, precisam incorporar um legado cultural em duplo sentido. Esse pensamento visa romper com a tradição de uma hierarquia do saber, direcionada à promoção do cientificismo. A recusa ao dogmatismo e ao doutrinarismo não é descaracterizar a ciência, desconsiderando a sua importância social, mas é admitir que todos os conhecimentos, sem exceção, são importantes, principalmente, para a realidade plural que se faz presente em nosso país (HINES, 2003).

Finalmente, boa parte dos alunos participantes da pesquisa afirma que observaram a relação da teoria científica com o seu cotidiano, uma vez que as atividades realizadas por essa pesquisa proporcionaram essa compreensão, pelo uso das frutas que fazem parte do 
seu dia a dia. Eles afirmaram estarem satisfeitos em participar da pesquisa e que as atividades foram muito interessantes, sendo diferentes das aulas exclusivamente teóricas. Assim, a grande maioria dos alunos se mostrou satisfeito com as atividades e todos os alunos desejaram que mais aulas práticas fossem realizadas na escola (Figura 3 e 4).

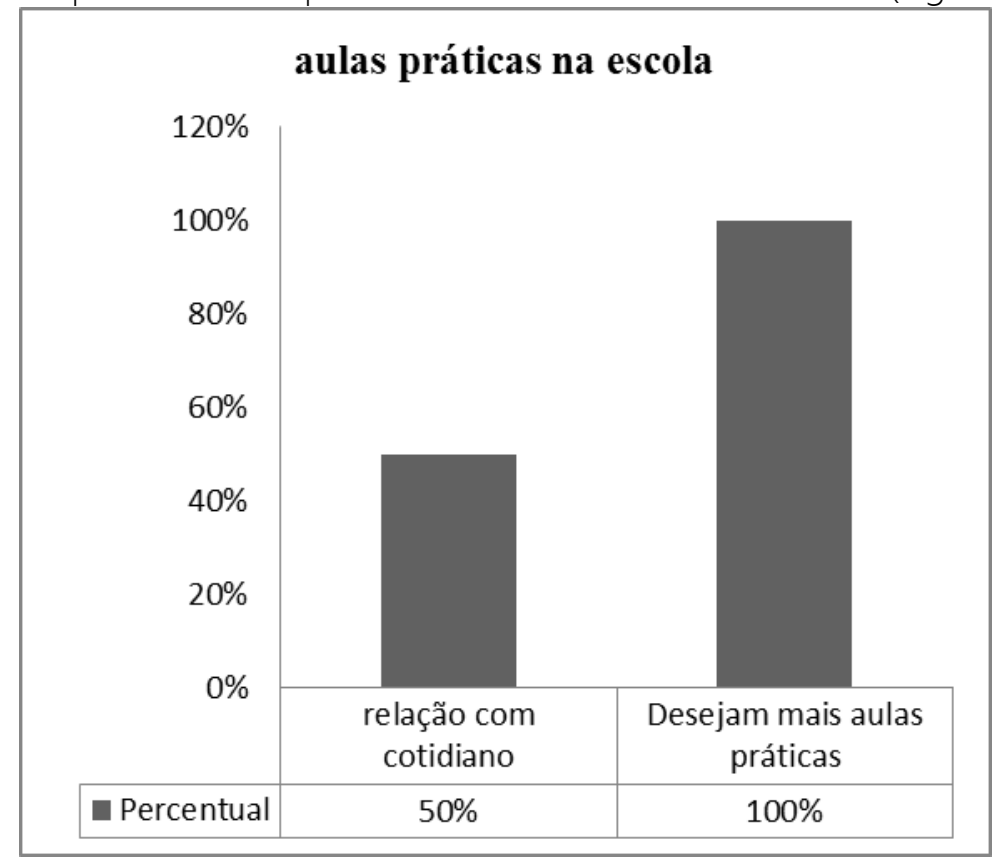

Figura 3 - Opinião a respeito das aulas práticas ministradas.

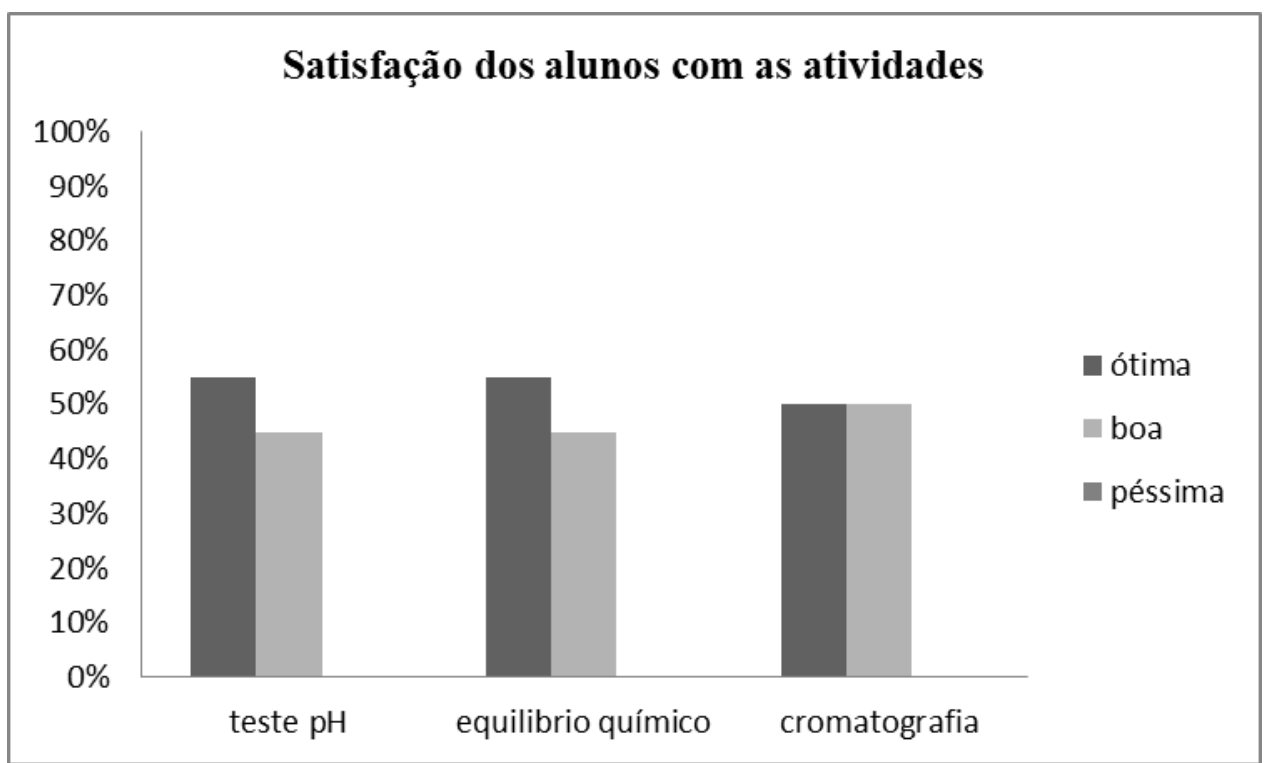

Figura 4 - Satisfação dos alunos com as atividades

\section{Considerações finais}

Esta pesquisa traz uma reflexão a respeito da formação dos licenciandos no ato das experiências vivenciadas durante os estágios supervisionados, e, também, discute a importância de aproximar a realidade cultural do aluno com a ecologia da sala de aula, principalmente, em um ambiente de extrema diversidade de saberes. Os professores de Ciências, em geral, precisam promover as relações entre os saberes local e global no 
exercício constante de sua práxis pedagógica, considerando que estamos diante do século das incertezas, e que, por isso, não se pode mais potencializar o pensamento fechado em sala de aula, mas está aberto para as novas possibilidades de ensino. Os conhecimentos são diversos, eles também estão presentes em toda a parte e se apresentam na diversidade cultural de um povo, havendo a necessidade de envolver a relação entre saberes e ciência (que Morin conceitua como "Sapiência"). A formação universitária precisa contemplar uma formação ampla e abrangente, dando abertura às novas possibilidades formativas, considerando que o homem apresenta-se como um ser social, biológico, psicológico e cultural, portanto, complexo. Assim, a educação precisa romper com o pensamento fragmentado, possibilitando-nos vivenciar uma nova era, tecida de novos diálogos. Evidentemente, que outras indagações surgem como novos problemas de pesquisa relacionados ao estudo, das quais estão: Por que o currículo das escolas brasileiras desconsidera o saber local, mesmo sendo um país culturalmente diverso? Como a educação intercultural poderia contribuir para o desenvolvimento do ensino de ciências na Amazônia? E, quais seriam as peculiaridades Amazônicas a ser consideradas para a formação de professores de Ciências na Amazônia?

\section{Referências}

AIKENHEAD, G. Toward a first nations cross-cultural Science and Technology Curriculum. Science Education, 81(2), 1997, p. 217-238.

ARRUDA, A. C. A. Química na Região Norte. Química Nova, 20 (especial), 1997.

BACHELARD, G. Os pensadores (a filosofia do não, o novo espírito científico, a poética do espaço), São Paulo: Abril cultural, 1978, p. 3-10.

BARBOSA, E. e BULCÃO, M. Bachelard - pedagogia da razão, pedagogia da imaginação. Petrópolis, RJ: Vozes, 2004, 102p.

BEJARANO, N.R.R. e CARVALHO, A.M.P. Educação química no Brasil: uma visão através das pesquisas e publicações da área. Educación Química, v. 11, 2000.

BOURDIEU, P. A economia das trocas simbólicas. $7^{a}$ ed., São Paulo: Perspectiva, 2013.

BOURDIEU, P. e PASSERON, J.C. A reprodução: elementos para uma teoria do sistema de ensino. $7^{a}$ ed., Petrópolis-RJ: Vozes, 2014, 275p.

BOURDIEU, P. Una invitación a la sociología reflexiva. $2^{\mathrm{a}}$ ed., Buenos Aires: Siglo Veintuino editores, 2012, p. 64-76.

BRASIL. Parâmetros Curriculares Nacionais + Ensino médio. Orientações educacionais complementares aos Parâmetros Curriculares Nacionais: Ciências da Natureza, Matemática e suas Tecnologias. Ministério da Educação, Secretaria de Educação Média e Tecnológica Brasília: SEMTEC, 2002.

BRITO, A.C.F., ALMEIDA, A.C.B., BEZERRA, I.A.R. e SILVIA, N.C. Utilização do extrato de açaí (Euterpe Oleracea Mart.) como indicador ácido-base natural no ensino de química. In: Anais do $51^{\circ}$ Congresso Brasileiro de Química, São Luís-Maranhão, 2011.

CARVALHO, A.M.P. e DARSIE, M.M.P. O inicio da formação do professor reflexivo. Revista da Faculdade de Educação, São Paulo, v. 22, n. 2, 1996, p. 90-108. 
COBERN, W.W. e AIKENHEAD, G. Cultural aspects of learning Science. Scientific Literacy and Cultural Studies Project, 13, 1997.

CONTRERAS, J. A autonomía de profesores. São Paulo: Cortez, 2002, 296p.

COSTA, T.O.G. e MESQUITA, D.W.O. Química na praça no Município de Parintins-Am. In: Anais do XV Encontro Nacional de Ensino de Química (ENEQ), Brasília, 2010.

COUTO, A.B.; RAMOS, L.A. e CARVALHO, E. T. Aplicação de Pigmentos de flores no ensino da química. Química Nova, 21 (2), 1998.

CRESWELL, J.W. Projeto de Pesquisa: métodos qualitativo, quantitativo e misto. $2^{\mathrm{a}}$ ed., Porto Alegre: Artmed, 2007, 248p.

EVANGELISTA, Y.S.P. e CHAVES, E.V. Ensino da Química: Metodologias utilizadas em temas transversais. Sistema de Gerenciamento de Conferencia (OCS), Anais do V CONNEPI, 2010, p. 2.

GADOTTI, M. Interdisciplinaridade, atitude e método. USP: Instituto Paulo Freire, 1999.

GADOTTI, M. Perspectivas atuais da educação. São Paulo: Perspectiva, v.14, n.2, 2000.

HERNÁNDEZ, F. e VENTURA, M. A organização do currículo por projetos de trabalho: o conhecimento é um caleidoscópio. $5^{a}$ ed., Porto Alegre: Artmed, 1998.

HINES, S.M. Multicultural Science Education-Theory, Practice, and Promise. New York: Peter Lang, 2003, 217p.

INSTITUTO BRASILEIRO DE GEOGRAFIA E ESTATÍSTICA - IBGE. Estimativa populacional do município de Coari-AM. Publicado em 2010. http://Acesso cidades.ibge.gov.br/xtras/perfil.php?codmun=130120 Acesso em: 15 de Setembro de 2016.

JAPIASSÚ, H. Interdisciplinaridade e patologia do saber. Rio de Janeiro: Imago, 1976.

JOHWAN, O.A., BASSO. A.S. e OLIVEIRA. G.B. A importância da Educação do processo do desenvolvimento local sustentável do município de Curitiba. UNIFAE, 2005.

LIMA, K.E.C. e TEIXEIRA, F.M. A atividade experimental como estrutura para o ensino de ciências naturais no CECINE nos anos de 1960 e 1970. In: Anais do XI Encontro Nacional de Pesquisa em Educação em Ciências - ENPEC, Florianópolis-SC, Anais ISSN: 1809-5100, 2017, p. 1-18.

LUGLE, A.M.C. e MAGALHÃES, C. O papel do estágio na formação do professor dos anos iniciais do ensino fundamental. Revista Eletrônica das Licenciaturas/UEL, $4^{a}$ edição, n. 4, v. 1, 2013, p. 119-128.

MILANESI, I. Estágio Supervisionado: Concepções e práticas em ambientes escolares. Educar em Revista, n. 46, 2012, p. 209-227.

MONTEIRO, E.P.; SILVIA, A.G. e NASCIMENTO, M.C. (2014). Estudo do extrato aquoso da casca da Bacaba (Oenocarpus bacaba Mart.) como indicador natural ácido-base. Latin American Journal of Science Education, v.1, edição 12012, 2014, p. 1-11.

MORIN, E. e PRIGOGINE, I. A sociedade em busca de valores. Para fugir à alternativa entre o ceticismo e o dogmatismo. Instituto Piaget: Epistemologia e Sociedade, 1996, 264p. 
MORIN, E. Introdução ao pensamento complexo. $4^{a}$ edição. Porto Alegre: Sulina, 2011, 120p.

OLIVEIRA, A.C.S., FREITAS, V.A.A., MARTINEZ, A.G., CAMPOS, V.R., SANTOS, V.O. e BARROS, I.C.L. Experimentação de Química voltada para o Ensino Médio em eventos científicos na cidade de Manaus. In: Anais do XV encontro Nacional de ensino da Química (ENEQ), Brasília-DF, 2010.

OLIVEIRA, J.R.S. Contribuições e abordagens das atividades experimentais no ensino de ciências: reunindo elementos para a prática docente. Acta Scientiae, v.12, n. 1, 2010, p. 139153.

PADILHA, R. P. Planejamento dialógico: como construir o projeto político-pedagógico da escola. São Paulo: Cortez, Instituto Paulo Freire, 2001.

PIMENTA, S.G. e LIMA, M.S.L. Estágio e Docência. São Paulo: Cortez, 2004.

PIMENTA, S.G. Formação de professores- saberes da docência e identidade do professor. Nuances, v. III, 1997, p. 5-14.

POZO, J.I. e CRESPO, M.A.G. A aprendizagem e o ensino de ciências: do conhecimento cotidiano ao conhecimento científico. $5^{\mathrm{a}}$ ed. Porto Alegre: Artmed, 2009.

SOARES, E.R. e COSTA, T.O,G. PIBID: Química contribuindo para a evolução do processo ensino-aprendizagem nas escolas públicas em Manaus/Am. In: Anais do XV Encontro Nacional de ensino da Química (ENEQ), Brasília-DF, 2010.

SOARES, R.T.C.; LIMA, M.E.C.C. e QUADROS, A.L. Importância e dificuldades do estágio curricular obrigatório. Minas Gerais: UFMG, 2007 (Monografia, Faculdade de Educação).

STENHOUSE, L. Investigación y desarrollo del curriculum. $1^{\text {a }}$ ed., editora Morata S.A. Colección, 1984, p. 194-221.

TAHA, M.S.; LOPES, C.S.C.; SOARES, E.L. e FOLMER, V. Experimentação como ferramenta pedagógica para o ensino de ciências. Experiências em ensino de ciências, v. 11, n. 1, 2016, p. 138-154.

TEIXEIRA, A.F. e MONTEIRO, D.D. Ensino de Química contextualizado através da mediação Tecnológica. In: Anais $1^{\circ}$ Congresso Paranaense de Educação em Química - CPEQUI, Londrina-Paraná, Universidade Estadual de Londrina, 2009.

ZABALA, A. Enfoque globalizador e pensamento complexo: uma proposta para o currículo escolar. Trad. Ernani Rosa. Porto Alegre: ARTMED, 2002.

ZUANON, A.C.A. O processo ensino - aprendizagem na perspectiva das relações entre: professor-aluno, aluno-conteúdo e aluno-aluno. Revista Ponto de Vista, 3 (X), 2000. 